\title{
Erratum to: Double primary cancer of the esophagus consisting of ectopic gastric mucosa-derived adenocarcinoma and squamous cell carcinoma: a first case report
}

\author{
Daisuke Iitaka · Hitoshi Fujiwara - Atsushi Shiozaki · Takeshi Kubota • \\ Takashi Ando · Yasutoshi Murayama - Shuhei Komatsu • Yoshiaki Kuriu • \\ Hisashi Ikoma - Masayoshi Nakanishi • Daisuke Ichikawa - Kazuma Okamoto • \\ Toshiya Ochiai · Yukihito Kokuba • Eigo Otsuji
}

Published online: 29 May 2012

(C) The Japan Esophageal Society and Springer 2012

Erratum to: Esophagus (2011) 8:303-309

DOI 10.1007/s10388-011-0296-2

The editors of Esophagus regret that the quality of Fig. 4 of the published article was not adequate for reproduction in the print version. More precisely focused images are shown on the following page.

The online version of the original article can be found under doi:10.1007/s10388-011-0296-2.

D. Iitaka · H. Fujiwara $(\bowtie) \cdot$ A. Shiozaki · T. Kubota ·

Y. Murayama · S. Komatsu · Y. Kuriu · H. Ikoma .

M. Nakanishi - D. Ichikawa · K. Okamoto · T. Ochiai .

Y. Kokuba · E. Otsuji

Division of Digestive Surgery, Department of Surgery,

Kyoto Prefectural University of Medicine, 465 Kajii-cho,

Kawaramachi-hirokoji, Kamigyo-ku, Kyoto 602-8566, Japan

e-mail: hfuji@koto.kpu-m.ac.jp

T. Ando

Department of Gastrointestinal Medicine, Social Insurance

Kyoto Hospital, 27 Shimofusa-cho, Oyama, Kita-ku,

Kyoto 603-8151, Japan 
A

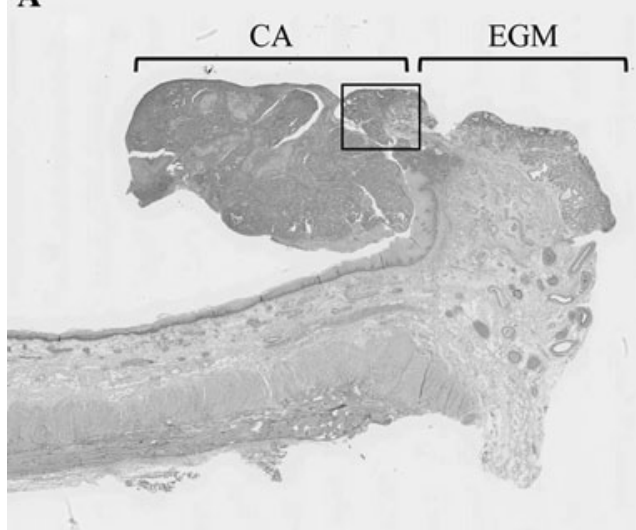

C

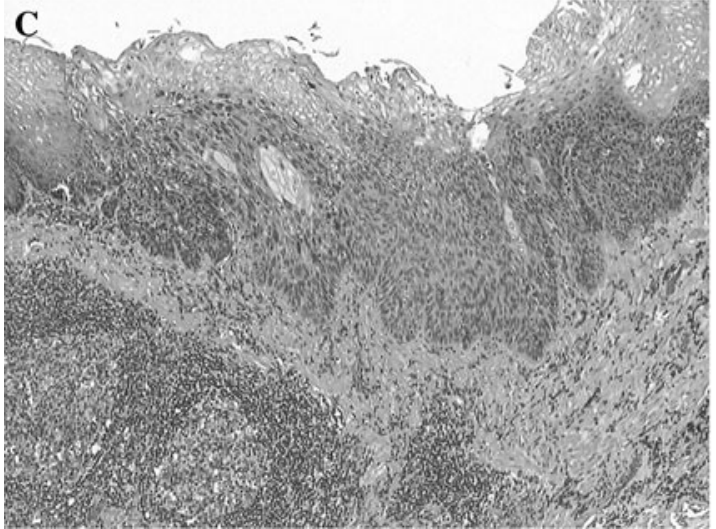

Fig. 4 Microscopic findings. Loupe view of the tumor in the cervical esophagus was shown in a. The tumor in the cervical esophagus was a well-differentiated adenocarcinoma $(C A)$ derived from ectopic gastric mucosa $(E G M)$ that had invaded the muscularis mucosa $(\mathbf{b})$. The

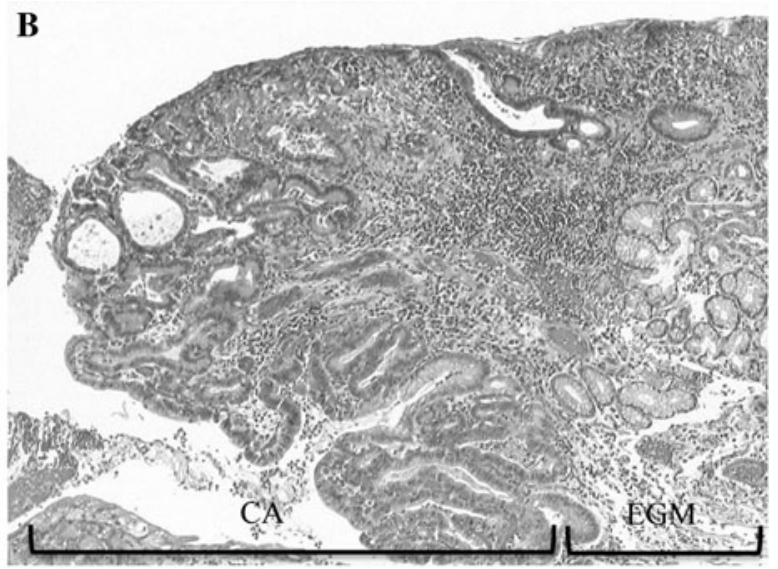

tumor in the distal esophagus was a squamous cell carcinoma that had invaded the proper mucosal layer (c) (hematoxylin and eosin, $\mathrm{H} \& \mathrm{E}$ $\times 40$ ). b Magnified view of the square area indicated in a 